\title{
An investigation of ion-plasma coatings solid particle erosion resistance at high-speed impact of gas-abrasive flow
}

\author{
A. F. Mednikov, G. V. Kachalin, A. V. Ryzhenkov \\ \& A. B. Tkhabisimov \\ Scientific Research Center "Wear resistance", \\ National Research University "MPEI”, Russian Federation
}

\begin{abstract}
The paper is devoted to experimental investigation of ion-plasma coatings solid particle erosion resistance at high-speed impact of gas-abrasive flow. The relevance of the investigation is stipulated by the still unsolved problem of steam turbines first stages' blades protection against solid particle erosion. The results of solid particle erosion investigations of three types of ion-plasma coatings (Ti-TiAlN, $\mathrm{Cr}-\mathrm{CrC}, \mathrm{NiCrC}-\mathrm{CrC}$ ), formed on samples of blade steels $20 \mathrm{Kh} 13$ and $15 \mathrm{Kh} 11 \mathrm{MF}$, are shown. Comparative tests showed the effectiveness of applying $\mathrm{NiCrC}-\mathrm{CrC}$ and $\mathrm{Cr}-\mathrm{CrC}$ coatings on blade steels $20 \mathrm{Kh} 13$ and $15 \mathrm{Kh} 11 \mathrm{MF}$ for solid particle erosion protection.

Keywords: rotor and stator blades, steam turbines, compressors, high-speed gas-abrasive flow, solid particle erosion, ion-plasma technologies, protective coatings, steel blade, experimental stand.
\end{abstract}

\section{Introduction}

The solid particle erosion (SPE) processes of the steam turbines' high (HPC) and medium (MPC) pressure cylinders flowing parts are the consequence of the highspeed impacts of solid particles on the constructive elements' functional surfaces, which lead to their destruction and thereby reduce their lives, emerge as a damage hazard, increase the cost of the damaged element restoration and repair. 
Over time, high-speed gas-abrasive flow destroys the constructive elements of the steam turbine, especially the rotor blades of the HPC and MPC first stages (see Fig. 1).
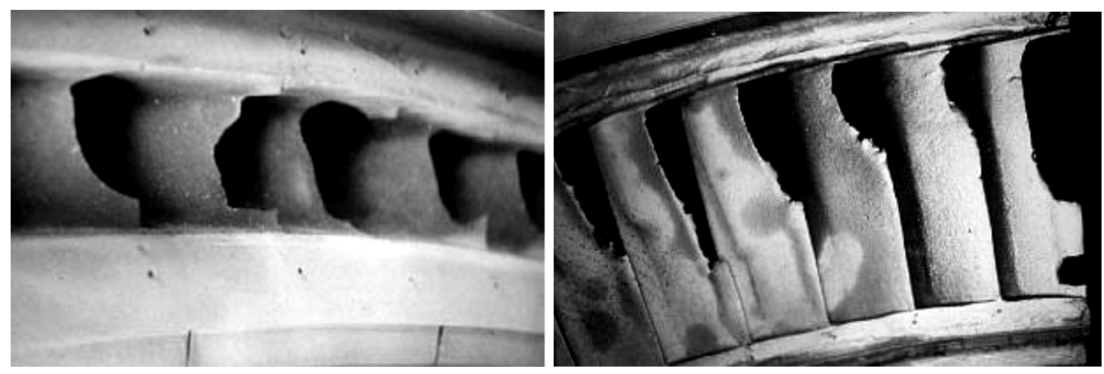

Figure 1: The destruction of the steam turbines HPC and MPC first stages rotor blades by solid particle erosion [1].

The characteristic feature of the SPE process is its rapid development: under certain operating conditions the destruction of steam turbine HPC rotor and stator blades' surface can occur for 1-3 years. Truhny and Lomakin [2] noted the decreasing of turbine coefficient of efficiency (COE) owing to SPE for every 5 years to $0.4 \%$ and as it is estimated by US experts [2], the average annual damage from SPE may be $1 \$$ per $1 \mathrm{~kW}$ of installed capacity.

SPE wear is caused by scoria fragments (magnetite $\mathrm{Fe}_{3} \mathrm{O}_{4}$ ), which are entrained by stream flow from the boiler superheater tubes and steam line pipes. Scoria fragments (solid particles) are found in steam inlet cells and HPC's and MPC's selectionless stages, in regenerative heaters or even in the condenser.

The main fundamental factors affecting the intensity of SPE wear are: the solid particles' size and hardness, their speed and angle of impact with blade surfaces, as well as the temperature of the gas-abrasive flow [3-5]. The temperature range of steam turbines' first stages blades operation is $520-560^{\circ} \mathrm{C}$, the solid particle size ranges from 10 to 300 microns; their hardness varies from 600 to $800 \mathrm{HB}$, particles' collisions velocity with a blade's surface: $50-250 \mathrm{~m} / \mathrm{s}$.

In recent years, the great quantity of methods to prevent power equipment SPE wear processes have been developed, but the problem remains relevant and leads to the creation of new ways of protection $[6,7]$.

Today, based on the turbine and compressor blades' service conditions, special attention is given to SPE processes' experimental investigations and the development of various passive protection methods.

\section{Ion-plasma coatings' application for turbine blade protection from solid particle erosion}

Currently, there is quite a large number of turbine blade protection methods from SPE, and all of them can be divided into active and passive. 
Various design decisions that have a dynamic impact on the gas-abrasive flow are usually related to the active protection methods, i.e. reducing the number of solid particles in the gas-abrasive flow or affecting the source of their formation.

Due to the rising demands to increase the power equipment service life, while retaining its high reliability, the development of relevant mechanical properties of blade steels improving by using so-called passive protection methods, including various variants of hardening or multifunctional coatings forming, is actual $[8,9]$.

Plating products with thin films of several microns' thickness is often an effective way to resist SPE. There are many types of protective coatings, which protect blades from SPE: electroplating, paint-and-lacquer coating, condensation-vacuum, etc.

The most advanced and common approach to increase SPE resistance is the creation of multilayer ion-plasma coatings, allowing one to increase both the mechanical strength and fracture toughness. Such coatings are obtained by forming two or more elements on a substrate.

Ion-plasma technology allows one to synthesize on the metal substrate the multilayer (with the layer thickness to $10 \mathrm{~nm}$ ) thin (30 microns) coatings with a nanocomposite structure (with $2 \mathrm{D}$ and $3 \mathrm{D}$ structures) from virtually unlimited matrix compositions of chemical elements of the 4-6 groups of Mendeleev's periodic system.

Perspective materials for ion-plasma SPE resistant coatings are nitrides, carbides and carbo-nitrides of refractory chemical elements $\mathrm{Ti}, \mathrm{Cr}, \mathrm{Ni}$, in particular, protective multilayer coatings based on the titanium-aluminum alloy nitride TiAlN, chromium alloy carbide $\mathrm{CrC}$ and nickel-chrome alloy carbide $\mathrm{NiCrC}$. SPE resistance of these coatings significantly depends on their formation conditions, physical, chemical and mechanical properties.

The aim of this research was the SPE resistance investigation of the ionplasma coatings with a structure of alternating layers of titanium-aluminum alloy and its nitride - TiAl-TiAlN, chromium and its carbide - $\mathrm{Cr}-\mathrm{CrC}$, nickel chromium alloy and chromium carbide $\mathrm{NiCr}-\mathrm{CrC}$, which were formed on samples of the blade steels $15 \mathrm{Kh} 11 \mathrm{MF}$ and $20 \mathrm{Kh} 13$.

\section{Equipment and methods of research}

Vacuum units "Hephaestus" (see Fig. 2) and "Hephaestus-HIPIMS" (NRU "MPEI" development), where one of the most modern and advanced methods of spraying materials - magnetron sputtering using planar magnetrons - have been used for ion-plasma coating formation. The principle of magnetron operation is in the target (cathode) sputtering by ions, which come from the direct current gas discharge over the target surface and accelerate toward the target. HIPIMS magnetron of vacuum unit "Hephaestus-HIPIMS" serves for ion cleaning by using a high-power pulsed discharge, which does not degrade the performance of the samples' surface roughness, and generating a high-quality layer with high adhesion. 


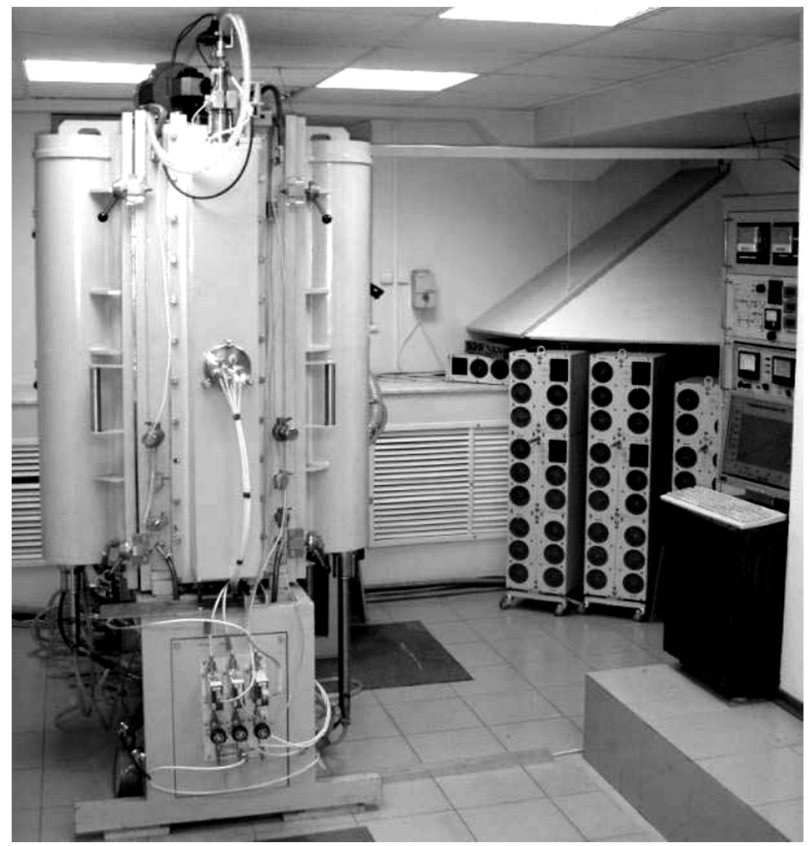

Figure 2: General view of the vacuum unit "Hephaestus" for ion-plasma coating formation.

The unit "Hephaestus" includes: vacuum chamber, a pump stand with three vacuum pumps, a spray-type system with four unbalanced magnetrons and a planar ion source with power units and the bias voltage unit, water cooling system, heater and current lead, a planetary mechanism for fixing and moving the products, a device for temperature measurement, the vacuum control devices and system of the installation control.

Coating formation occurs in a vacuum chamber, in which a vacuum is achieved by means of a pump and the necessary pressure is continuously maintained. The value of working (technological) pressure is determined by the physics and technology of the process and is in the range of 0.01-0.5 $\mathrm{Pa}$. The ultimate vacuum achieved in the installation is $10^{-4} \mathrm{~Pa}$. The following gases used during the process of coating formation: argon is a plasma-forming gas and it is used to create and maintain an electric discharge in a vacuum; nitrogen, oxygen, hydrocarbons and others - reaction gases for obtaining compounds (nitrides, carbides, oxides and others).

The process of ion-plasma coating formation included the following main stages: pre-treatment of the sample surface (polishing, impurities removal from the surface and degreasing) and loading them into the chamber; pumping of the chamber to a high vacuum with preheating; ion cleaning and coating formation on the sample surface.

TiAl, Cr, NiCr alloys were used as cathode-target materials; high-purity argon was used for creating and maintaining a low-pressure gas discharge, high purity 
carbon and nitrogen were used for nitrides and carbides of TiAl-N, Cr-C, $\mathrm{NiCrC} / \mathrm{CrC}$ synthesis.

The chamber was pumped to a high vacuum (pressure not higher than $5 \times 10^{-3} \mathrm{~Pa}$ ) with preheating for intensification of chamber and samples degassing process before forming the listed kinds of coatings. After pumping the plasmaforming gas (argon) supplied into the vacuum chamber up to a pressure of 0.25 $0.4 \mathrm{~Pa}$, and sample ion cleaning was performed for removing the oxide film and for surface activation. A negative voltage in the range from 800 to $1250 \mathrm{~V}$ was applied to the product for 20-40 minutes. Next, the processes of ion-plasma coating formation were carried out.

NRU "MPEI" has a complex of research equipment [10], which is used to conduct comprehensive investigations of formed coatings' properties, such as composition and structure of coatings; measurement of thickness, roughness, microhardness of coatings, etc.

Field emission scanning electron microscope TESCAN MIRA 3 LMU is used to study the structure and surface topography of formed coatings. Transverse metallographic sections were made to study the coating structure and structure of the base material using microscopic methods and to study composition of the coating by energy dispersive microanalysis. The available complex of equipment for the manufacture of metallographic sections includes an abrasive cutting machine with a linearly movable cutting system POWERMET 3000 (Buehler $\mathrm{GmbH}$ ), electro-hydraulic press SIMPLIMET 1000 (Buehler $\mathrm{GmbH}$ ), grinding polishing mount BETA/1 (Buehler $\mathrm{GmbH}$ ). Control and determination of the coatings' thickness were carried out in two ways - by transverse and spherical sections using a scanning electron microscope TESCAN MIRA 3 LMU and laboratory complex Calotest (CSM Instruments) to determine the thickness of coatings and spherical sections' manufacturing. The surface roughness of the samples was measured using a portable profilometer Surftest SJ-210 (Mitutoyo). Measurements of coatings' microhardness were carried out using a MHT-10 (Anton Paar $\mathrm{GmbH}$ ), mounted on an optical microscope Axiovert 25CA, with application of images analysis laboratory complex for optical microscope Axiovert 25CA (Carl Zeiss Mikroskopie).

A jet blasting-type experimental test rig, which simulates various conditions of solid particle interaction with the surface of structural materials [11] was used for SPE resistance research of coatings. The experimental test rig allows the carrying out of SPE resistance investigations of the materials and coatings in a wide range of solid particle interaction parameters with the sample surface (see Table 1).

Table 1: Main characteristics of experimental test rig.

\begin{tabular}{|c|c|}
\hline Parameter & Value \\
\hline Average flow velocity, $\mathrm{m} / \mathrm{s}$ & up to 200 \\
\hline Angle of attack, deg. & $10-90$ \\
\hline Sample temperature, ${ }^{\circ} \mathrm{C}$ & up to 600 \\
\hline
\end{tabular}


The experimental test rig operates on the following principle. Compressed air from the compressor supplies the filter regulator where it cleans various suspensions and impurities and reduces pressure, the value of which is controlled by an absolute manometer. The flow-control unit mounted further on the path is used for monitoring the airflow rate, the value of which determines the flow velocity. Further flow enters the mixing chamber using an air supply line. Hard solid particles with a certain flow rate, the value of which is controlled by a solid particles' doser software module, enter the mixing chamber using a solid particles' supply line. A gas-abrasive stream exits the stabilizing tube after mixing chamber and interacts with the surface of an experimental sample. The angle of the sample position relative to the flow axis is controlled by graduated scale on the sample holder. Electrocorundum $\mathrm{Al}_{2} \mathrm{O}_{3}$ particles with average size 250-300 microns are used as solid particles.

Comparative SPE resistance tests of samples of uncoated and coated blade steels $20 \mathrm{Kh} 13$ and $15 \mathrm{Kh} 11 \mathrm{MF}$ were conducted with the application of an experimental test rig. Investigations were carried out with a certain time step test, which was 5 minutes. To construct each dependence of the SPE intensity wear of the time test at least three experimental samples were used. Mass loss from the sample was recorded after each time test and mass loss from the sample was estimated relative to its initial mass.

The incubation period duration of the SPE process $\left(t^{\text {inc }}\right)$ was determined graphically by laying the tangent to the curve on the steady wear rate area to its intersection with the x-axis. Relative SPE resistance on the duration of the incubation period was determined by the ratio of the duration of the incubation period of the coated material to the duration of the incubation period of uncoated material, taken as a unit.

Relative solid particle erosion resistance on the area with an established wear rate $\left(\Delta \mathrm{m}^{\mathrm{st}}\right)$ was determined by comparing the value of mass loss of the coated material to the value of mass loss of material without a coating, taken as a unit for the exposure time on the rig, which was 60 minutes.

\section{Investigation results}

As a result of a comprehensive investigation of protective coatings' properties, including their composition, thickness, structure, microhardness determination, it was found that:

- coatings are multilayer; the thickness of the formed coatings varies from 7 to 12 microns;

- coatings are characterized by a columnar and grain structure, coupled with a layered structure;

- the main element of the TiAl-TiAlN coating is titanium and aluminum, nitride layers contain $83-84 \%$ titanium and $4.5-5.3 \%$ nitrogen;

- the main element of the $\mathrm{Cr}-\mathrm{CrC}$ coating is chromium, carbide layers contain 89.4-92.2\% chromium and 6.2-9.5\% carbon;

- the coating $\mathrm{NiCr} / \mathrm{Cr}-\mathrm{NiCrC} / \mathrm{CrC}$ contains $\mathrm{Cr}, \mathrm{Ni}, \mathrm{C}$, and a small content of $\mathrm{Fe}$, $\mathrm{Al}$, carbide layers contain $56.3-59.1 \%$ chromium and $32.8-35 \%$ nickel; 
- coatings have a grain structure, the grain size is in the range from 20-100 nm; - microhardness $\left(\mathrm{H}_{0,05}\right)$ of coatings varies from 1100 to $1400 \mathrm{HV}$.

The images of transverse metallographic sections of the blade steel 20Kh13 samples with various protective coatings are shown in Figure 3.

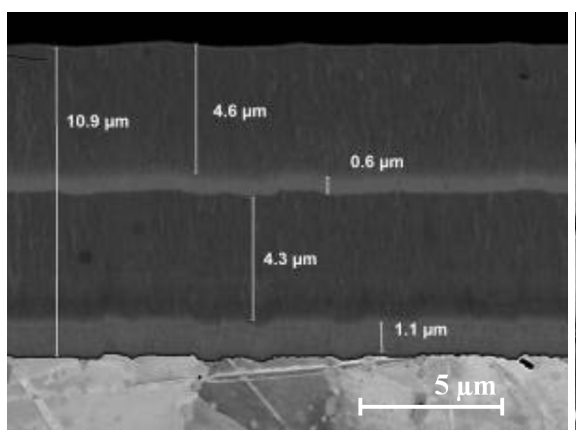

(a)

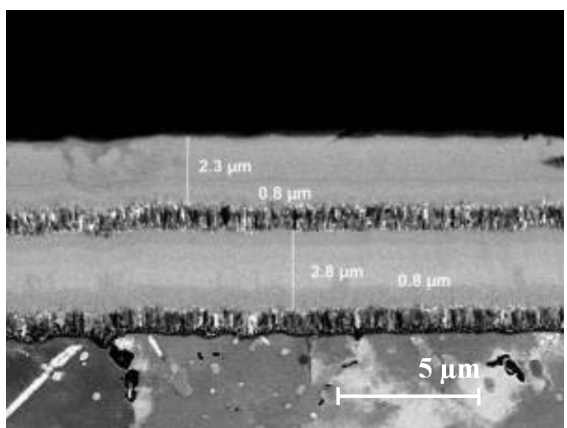

(b)

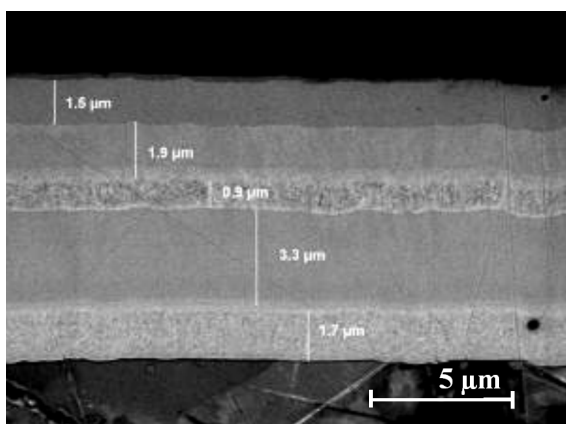

(c)

Figure 3: The images of the transverse sections of the blade steel 20Kh13 samples with various protective coatings: (a) TiAl-TiAlN; (b) $\mathrm{Cr}-\mathrm{CrC}$; (c) $\mathrm{NiCr} / \mathrm{Cr}-\mathrm{NiCrC} / \mathrm{CrC}$.

SPE resistance comparative tests of blade steels $20 \mathrm{Kh} 13$ and $15 \mathrm{Kh} 11 \mathrm{MF}$ samples with coatings and without coatings were conducted on the abrasive test rig NRU "MPEI" with the following parameters: average speed of gas-abrasive flow $-170 \mathrm{~m} / \mathrm{s}$, the angle of the solid particles collision with the sample surface $-30^{\circ}$, the sample surface temperature $-25^{\circ} \mathrm{C}$. The obtained results of comparative tests are given in Figures 4 and 5 . The results of the above types of steels and protective coatings' SPE resistance determination are shown in Figures 6 and 7. 


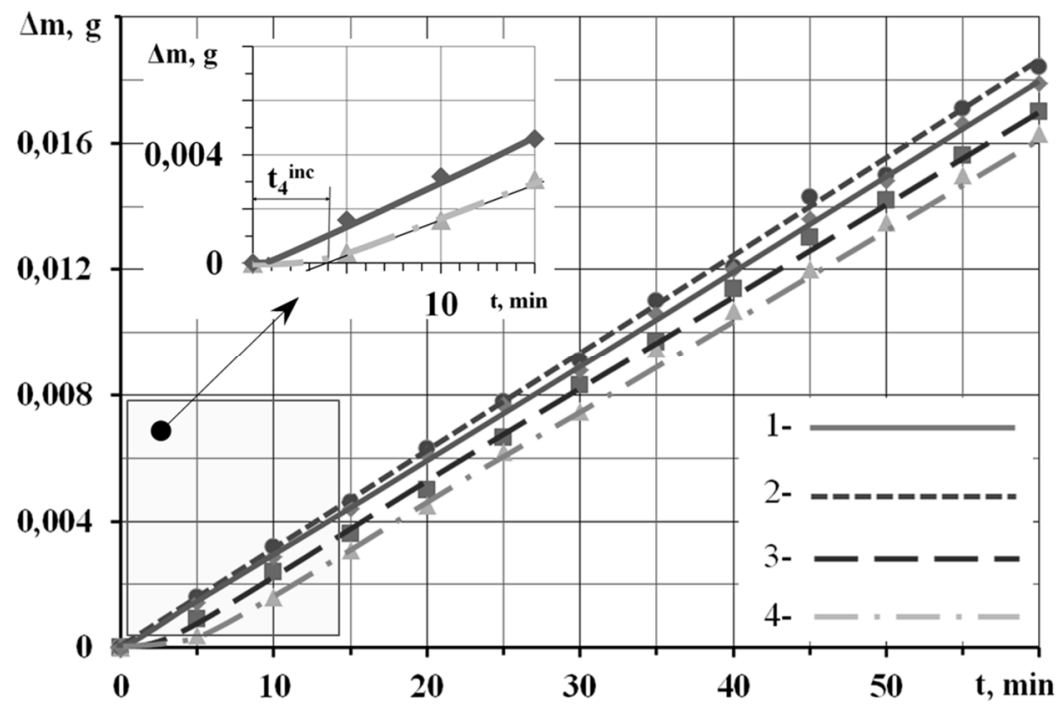

Figure 4: The solid particle erosion wear intensity of steel $15 \mathrm{Kh} 11 \mathrm{MF}$ and ion-plasma coatings: 1 - 15Kh11MF; 2 - 15Kh11MF with TiAlTiAlN coating; 3 - 15Kh11MF with $\mathrm{NiCr} / \mathrm{Cr}-\mathrm{NiCrC} / \mathrm{CrC}$ coating; $4-15 \mathrm{Kh} 11 \mathrm{MF}$ with $\mathrm{Cr}-\mathrm{CrC}$ coating.

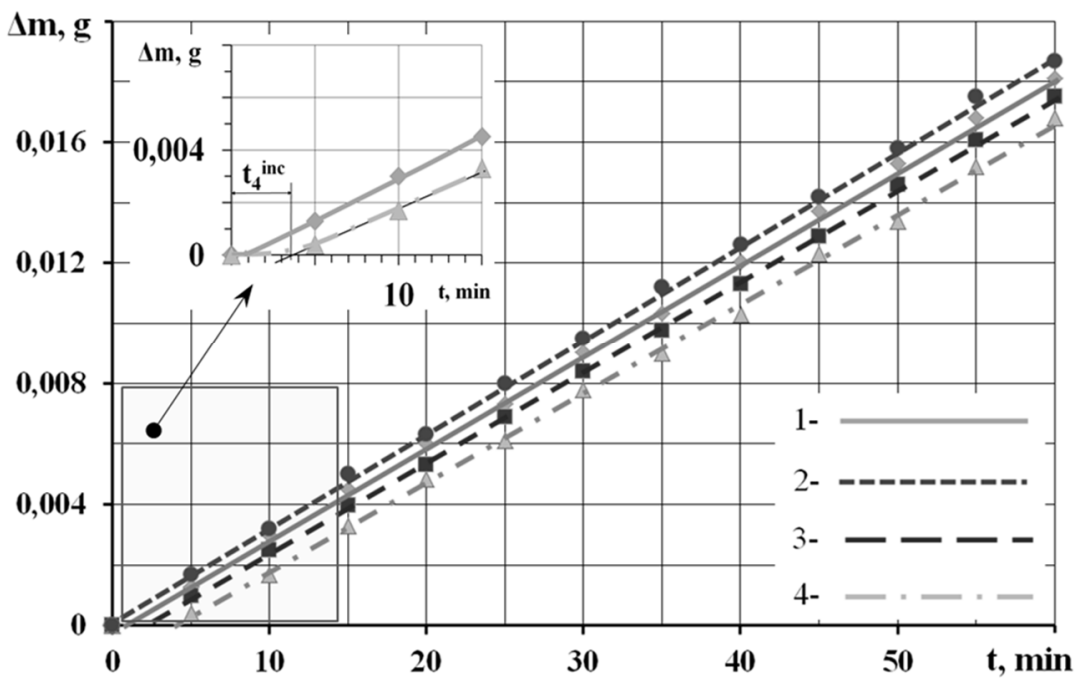

Figure 5: The solid particle erosion wear intensity of steel $20 \mathrm{Kh} 13$ and ion-plasma coatings: $1-20 \mathrm{Kh} 13 ; 2-20 \mathrm{Kh} 13$ with TiAl-TiAlN coating; $3-20 \mathrm{Kh} 13$ with $\mathrm{NiCr} / \mathrm{Cr}-\mathrm{NiCrC} / \mathrm{CrC}$ coating; $4-20 \mathrm{Kh} 13$ with $\mathrm{Cr}-\mathrm{CrC}$ coating. 


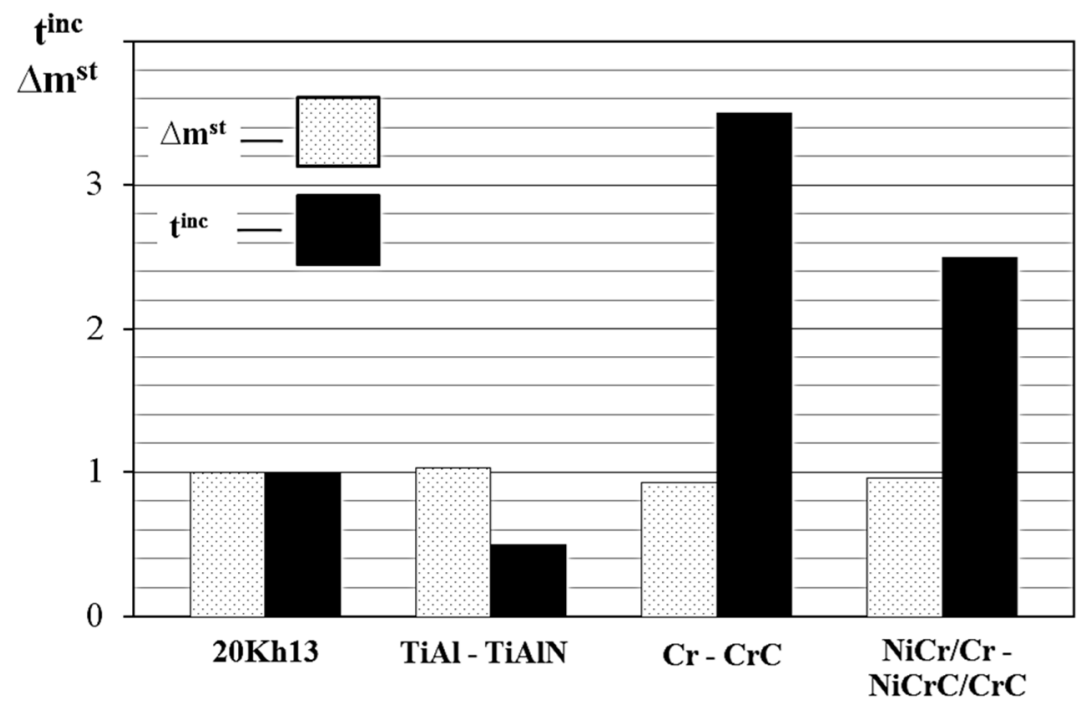

Figure 6: Relative solid particle erosion resistance of the steel $20 \mathrm{Kh} 13$ and protective coatings for the duration of the incubation period $\mathrm{t}^{\text {inc }}$ and mass loss $\Delta \mathrm{m}^{\text {st }}$ on the steady wear rate.

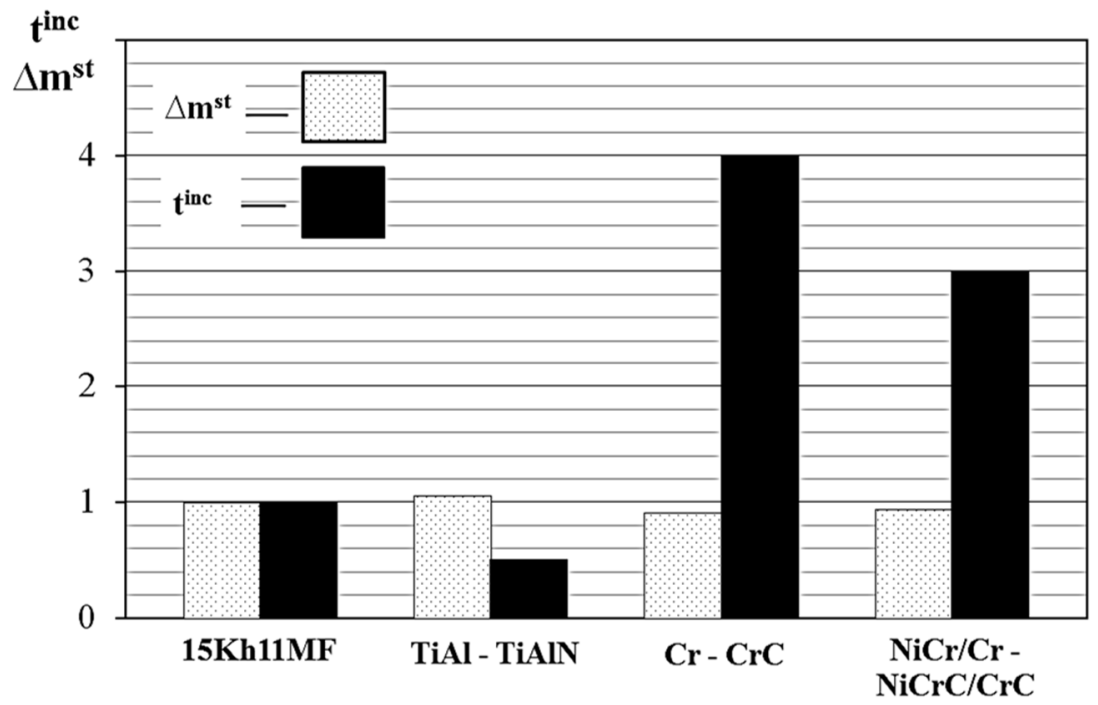

Figure 7: Relative solid particle erosion resistance of the steel $15 \mathrm{Kh} 11 \mathrm{MF}$ and protective coatings for the duration of the incubation period $\mathrm{t}^{\text {inc }}$ and mass loss $\Delta \mathrm{m}^{\text {st }}$ on the steady wear rate. 
Investigated types of protective coatings revealed the following results for their SPE resistance towards the incubation period duration $t^{\text {inc }}$ of the base material:

- the Cr-CrC coating increases up to 3.5 times the resistance of the $20 \mathrm{Kh} 13$ steel and up to 4 times the resistance of the $15 \mathrm{Kh} 11 \mathrm{MF}$ steel;

- the $\mathrm{NiCr} / \mathrm{Cr}-\mathrm{NiCrC} / \mathrm{CrC}$ coating increases up to 2.5 times the resistance of the $20 \mathrm{Kh} 13$ steel and up to and 3.5 times the resistance of the $15 \mathrm{Kh} 11 \mathrm{MF}$ steel;

- the TiAl-TiAlN coating reduces down to 2 times the resistance of the $20 \mathrm{Kh} 13$ steel and $15 \mathrm{Kh} 11 \mathrm{MF}$ steel.

Investigated types of protective coatings showed the following results for their SPE resistance towards the base material mass loss at the area with steady wear rate $\Delta \mathrm{m}^{\text {st: }}$

- the SPE resistance of the $\mathrm{Cr}-\mathrm{CrC}$ coating up to $10 \%$ higher than the resistance of the $20 \mathrm{Kh} 13$ steel and $15 \mathrm{Kh} 11 \mathrm{MF}$ steel;

- the SPE resistance of the $\mathrm{NiCr} / \mathrm{Cr}-\mathrm{NiCrC} / \mathrm{CrC}$ coating up to $5 \%$ higher than the resistance of the $20 \mathrm{Kh} 13$ steel and $15 \mathrm{Kh} 11 \mathrm{MF}$ steel;

- the SPE resistance of the TiAl-TiAlN coating down to 5\% lower than the resistance of the $20 \mathrm{Kh} 13$ steel and $15 \mathrm{Kh} 11 \mathrm{MF}$ steel.

\section{Conclusions}

On the samples of blade steels $20 \mathrm{Kh} 13$ steel and $15 \mathrm{Kh} 11 \mathrm{MF}$ three types of ionplasma coatings were formed (on the basis of $\mathrm{TiAl}, \mathrm{Cr}, \mathrm{NiCr}$ ) and experimental investigation carried out of their solid particle erosion resistance at high-speed impact of gas-abrasive flow (average speed of gas-abrasive flow $-170 \mathrm{~m} / \mathrm{s}$, the angle of the solid particles collision with the sample surface $-30^{\circ}$, the sample surface temperature $-25^{\circ} \mathrm{C}$ ). SPE resistance comparative tests have shown the effectiveness of $\mathrm{NiCr} / \mathrm{Cr}-\mathrm{NiCrC} / \mathrm{CrC}$ and $\mathrm{Cr}-\mathrm{CrC}$ coatings both on the blade steels $20 \mathrm{Kh} 13$ and $15 \mathrm{Kh} 11 \mathrm{MF}$. The best type of coating that increases SPE resistance of both substrates up to 3.5-4 times towards the incubation period duration is $\mathrm{Cr}-\mathrm{CrC}$. Also $\mathrm{NiCr} / \mathrm{Cr}-\mathrm{NiCrC} / \mathrm{CrC}$ coating shows good results in increasing SPE resistance of both substrates towards the incubation period duration up to $2.5-3.5$ times.

Increasing the duration of the SPE incubation period of blade steels by using ion-plasma coatings, including, for example, the investigated coatings will improve the service life of the blades before the destruction of their functional surfaces.

During the operational period of the steam turbines' first stages blades mainly works on a steady period of the SPE process, which certainly suggests further research, development and creation of coatings, that increase not only the duration of the incubation period, but also reduce the destruction of the blades' surfaces on the steady period of the erosion process.

As a part of the further continuation of this work, it is planned to conduct experimental investigations of SPE resistance and surface fracture dynamics of the considered blade steels and protective coatings at high temperatures (up to 
$550^{\circ} \mathrm{C}$ ), corresponding to the operating conditions of the steam turbines' HPC's and MPC's first stages blades.

\section{Acknowledgement}

Intermediate results were obtained with the financial support of the Ministry of Education and Science of the Russian Federation as the part of the agreement № 14.574.21.0011 of 17 June 2014 (unique identification number RFMEFI57414X0011).

\section{References}

[1] http://www.slideshare.net/shivajichoudhury

[2] A.D. Truhny, B.V. Lomakin Cogeneration steam turbine and turbine plant: a manual for high schools, M.: MPEI Publishing, 2002.

[3] A. Campos-Amezcua, Z. Mazur, A. Gallegos-Munoz, A. RomeroColmenero, J. Manuel Riesco-Ar, J. Martın Medina-Flore, Numerical study of erosion due to solid particles in steam turbine blades, Numerical Heat Transfer, Part A, 53, 667-684, 2008.

[4] J.R. Laguna-Camacho, A. Marquina-Chavez, J.V. Mendez-Mendez, M. Vite-Torres, E.A. Gallardo-Hernandez, Solid particle erosion of AISI 304, 316 and 420 stainless steels, Wear, 301, 398-405, 2013.

[5] Y.I. Oka, M. Nishimura, K. Nagahashi, M. Matsumura Control and Evaluation of Particle Impact Conditions in a Sand Erosion Test Facility Wear, 250(2), pp. 736-743, 2001.

[6] V.A. Ryzhenkov, G.V. Kachalin, S.I. Pogorelov, O.V. Starikova, B.G. Ter-Arutyunov Perspectives of using ion-plasma coatings to improve wear resistance of power equipment elements, New in the Russian power: the monthly e-zine, Energy-press, 3, pp. 16-25, 2004.

[7] P.R. Dolzhansky, S.E. Dobrokhotov Increasing the operational reliability of the turbines T-250/300-240 last stages rotor blades, Reliability and security of energy, 1, 2008.

[8] V.A. Ryzhenkov, V.A. Fedorov, G.V. Kachalin, A.F. Mednikov Increasing the corrosion resistance of high levels of turbine blades, Reliability and security of energy, 2 (5), pp. 34-39, 2009.

[9] G.V. Kachalin, V.A. Ryzhenkov, B.G. Ter-Arutyunov, A.F. Mednikov Hardening of stop and control valves elements by using ion-plasma technologies, Metal Technology, 4, pp. 19-21, 2007.

[10] G.V. Kachalin, V.A. Ryzhenkov, A.F. Mednikov Innovative technological complex for multi-ion-plasma coatings formation on the large valve elements surfaces, Natural and Technical Sciences, 2, pp. 168-174, 2013.

[11] A.V. Ryzhenkov, G.V. Kachalin, A.F. Mednikov, A.B. Tkhabisimov The investigation of construction materials and protective coatings wear resistance to solid particle erosion, Modern Applied Science, 9(4), pp. 85$95,2015$. 